\title{
Detection and genotyping of meningococci using a nested PCR approach
}

\author{
M. A. Diggle ${ }^{1}$ and S. C. Clarke $e^{1,2}$ \\ ${ }^{1}$ Scottish Meningococcus and Pneumococcus Reference Laboratory, North Glasgow University \\ Hospitals NHS Trust, Stobhill Hospital, Balornock Road, Glasgow G21 3UW, UK \\ ${ }^{2}$ Faculty of Biomedical and Life Sciences, University of Glasgow, UK
}

Correspondence

S. C. Clarke

stuart.clarke@northglasgow.

scot.nhs.uk

Received 25 July 2002

Accepted 29 August 2002
An effective vaccine against Neisseria meningitidis serogroup B is required. Outer-membrane protein vaccines have been developed, which may provide protection against common circulating serotypes and serosubtypes in some countries. However, limited genosubtyping data are available because most laboratories use mAbs directed against a limited number of specific serotypes and serosubtypes and laboratories do not genosubtype directly from body fluids due to the lack of a sensitive PCR method. A nested PCR was therefore developed that enables the amplification of the porA gene directly from clinical samples and has the required sensitivity for nucleotide sequencing of the three main variable regions, VR1, VR2 and VR3. Data were compared with those from culturebased nucleotide sequencing, and the use of this method increased the availability of genosubtype information by $45 \%$, thereby indicating the impact that this methodology has on the data provided and the implications for vaccine design.

\section{INTRODUCTION}

Meningococcal disease remains a significant public health problem, and a vaccine against Neisseria meningitidis serogroup B is urgently needed (Rosenstein et al., 2001). However, the use of a capsule-based vaccine is unlikely because the meningococcal polysaccharide is identical to a human carbohydrate $[\alpha(2 \rightarrow 8) N$-acetyl neuraminic acid or polysialic acid] (Finne et al., 1987; Hayrinen et al., 1995). Vaccines based on other antigens therefore require development and the outer-membrane proteins (OMPs) of the meningococcus have been investigated (Rosenstein et al., 2001; Al'Aldeen \& Cartwright, 1996). Although OMP-based vaccines are not the solution for combating serogroup $B$ meningococcal infection, they may be useful in some circumstances (Al'Aldeen \& Cartwright, 1996; Rappuoli, 2001). However, such proteins are highly antigenically variable, and an OMP vaccine cannot protect against all serotypes and serosubtypes of $N$. meningitidis. Therefore, selected OMPs must be used, based on the prevalent serotypes and serosubtypes in a given population. However, to develop such vaccines, high-quality data must be gained to determine such prevalence. To date, the characterization of meningococci has relied on serogrouping, serotyping and serosubtyping using serological methods, thereby limiting the designation of serotypes and serosubtypes because a

Abbreviations: CSF, cerebrospinal fluid; OMP, outer-membrane protein; SMPRL, Scottish Meningococcus and Pneumococcus Reference Laboratory; VR, variable region. panel of mAbs is used. Newer nucleotide sequence methods, based on the detection and sequencing of the por $B$ and por $A$ genes for serotype (class 2/3 OMP) and serosubtype (class 1 OMP), respectively, have led to a better understanding of the variability of these proteins (Urwin et al., 1998a, b, c; Clarke et al., 2001a; Jelfs et al., 2000; Molling et al., 2000; Feavers et al., 1996; Saunders et al., 1993; Smith et al., 1995). However, most of these methods are only useful when $N$. meningitidis has been isolated from blood or cerebrospinal fluid (CSF) and they therefore rely on the availability of a culture (Jelfs et al., 2000; Feavers et al., 1996). Other methods rely on sufficient numbers of meningococci being present in body fluids (Urwin et al., 1998a; Clarke et al., 2001a; Saunders et al., 1993). Although the PCR has been used with great success for the laboratory confirmation of meningococcal disease (Ni et al., 1992; Guiver et al., 2000; Corless et al., 2001; Diggle et al., 2001a), some methods have lacked the sensitivity required for the detection of DNA and subsequent nucleotide sequence analysis from body fluids. With the success of clinical trials with candidate OMP vaccines, there is a need for better understanding of the epidemiology of porA sequence variation. Although there are eight exposed surface loops (I-VIII) within porA (van der Ley et al., 1991), to date, most variation has been observed within loops I, IV and V, otherwise known as variable regions (VRs) 1, 2 and 3 (Molling et al., 2000; van der Ley et al., 1991; Maiden et al., 1991; McGuinness et al., 1993; Clarke et al., 2001b). We have therefore developed a nested PCR method for amplification of the N. meningitidis porA gene directly from body fluids and sequenced three variable regions of interest, VRs 1, 2 and 3, to 
indicate their sequence variability. We have compared this information with data gained from culture-based sequencing only and also discussed the impact that this methodology has on the data provided and the implications for vaccine design.

\section{METHODS}

Patients and specimens. All patients with suspected meningococcal disease in Scotland between January and June 2001 were included in this study. Samples were sent from microbiology diagnostic laboratories throughout Scotland to the Scottish Meningococcus and Pneumococcus Reference Laboratory (SMPRL) and consisted of N. meningitidis cultures isolated from blood or CSF or samples of body fluid or tissue for meningococcal PCR.

Phenotypic characterization of $\boldsymbol{N}$. meningitidis strains. All strains were isolated on horse-blood agar (Oxoid) at $37^{\circ} \mathrm{C}$ in an atmosphere of $5 \% \mathrm{CO}_{2}$. Serogrouping of N. meningitidis was performed by latex agglutination, co-agglutination and siaD PCR as described previously (Eldridge et al., 1978; Olcen et al., 1975; Borrow et al., 1997, 1998a). Serotyping and serosubtyping were performed as described previously (Frasch et al., 1985; Clarke et al., 2002).

Genotypic characterization of $\boldsymbol{N}$. meningitidis strains. A liquidhandling robot, the RoboAmp-4204 (MWG-Biotech), was used for all PCR and sequencing set-up procedures. This robot possesses four washable tips, two integrated thermocyclers and an integrated vacuum manifold for high-throughput liquid handling, PCR and DNA cleanup, respectively. An automated 96-capillary DNA sequencer, the Molecular Dynamics MegaBACE 1000 (Amersham Pharmacia Biotech), was used for automated DNA sequencing. Programming of the RoboAmp-4204 liquid-handling system was performed according to the manufacturer's instructions. This allowed the automation of most of the procedures required for the DNA amplification of the porA gene and subsequent sequence-labelling from meningococcal isolates. Clinical isolates of $N$. meningitidis were cultured on horse-blood agar (Oxoid) and incubated overnight in the presence of $5 \% \mathrm{CO}_{2}$ at $37^{\circ} \mathrm{C}$. A few fresh colonies were suspended in $0.5 \mathrm{ml} 18-\mathrm{M} \Omega$ distilled water and boiled for $10 \mathrm{~min}$. The suspension was centrifuged at 15000 r.p.m. for $2 \mathrm{~min}$ and the supernatant was used as a source for the detection of meningococcal DNA. All PCR reagents were maintained at $4{ }^{\circ} \mathrm{C}$ on the platform. Each PCR was performed in a final volume of $50 \mu$ using $1 \cdot 1 \times$ Reddymix PCR master mix, containing 1.25 U Taq DNA polymerase (ABgene), $75 \mathrm{mM}$ Tris/ $\mathrm{HCl}\left(\mathrm{pH} 8.8\right.$ at $\left.25^{\circ} \mathrm{C}\right), 20 \mathrm{mM}\left(\mathrm{NH}_{4}\right)_{2} \mathrm{SO}_{4}, 1.5 \mathrm{mM}$
$\mathrm{MgCl}_{2}, 0 \cdot 01 \%$ (v/v) Tween 20 and $0.2 \mathrm{mM}$ each of dATP, dCTP, dGTP and TTP. For a $50 \mu \mathrm{l}$ reaction, $45 \mu \mathrm{l}$ PCR master mix and $1 \mu \mathrm{l}$ of each porA primer, PorA-F and PorA-R (Table 1), were added to produce a master mix volume of $47 \mu$. These pre-prepared master mixes were placed on the RoboAmp-4200 refrigerated reagent rack and the DNA samples were placed on the sample area. Within a refrigerated 96-well microtitre plate, $47 \mu \mathrm{l}$ master mix was added automatically to appropriate wells using a washable tip along with $3 \mu$ l DNA preparation, making a final $50 \mu \mathrm{l}$ reaction mixture. After each stage of the set-up, the washable tip was washed automatically with $2 \mathrm{ml} 18-\mathrm{M} \Omega$ distilled water. The microtitre plate was placed automatically into the integrated MWG-Biotech Primus 96 thermocycler. The PCR conditions were described previously (Clarke et al., 2001b) and were 25 cycles of $95^{\circ} \mathrm{C}$ for $1 \mathrm{~min}, 60^{\circ} \mathrm{C}$ for $1 \mathrm{~min}$ and $72{ }^{\circ} \mathrm{C}$ for $2 \mathrm{~min}$ followed by one cycle of $72{ }^{\circ} \mathrm{C}$ for $2 \mathrm{~min}$. After the PCR, the microtitre plate was removed automatically from the thermocycler to a refrigerated block.

Meningococcal PCR from body fluids. Meningococcal PCR requests were received from patients with suspected meningococcal disease. DNA was extracted from whole blood or serum using the Nucleospin Blood kit (ABgene). CSF samples were boiled for $5 \mathrm{~min}$ and centrifuged at 15000 r.p.m. for $2 \mathrm{~min}$ and the supernatant was used in the PCR. DNA samples were then processed for a routine IS1106 PCR assay (Ni et al., 1992; Newcombe et al., 1996) followed by the ctrA PCR assay (Diggle et al., 2001a) as described previously but performed on another liquidhandling robot, the RoboAmp-4200 PE, which possesses a non-crosscontamination (NCC) system. The reactions were set up as for the porA PCR but respectively with IS1106 and $c t r A$ primers (Table 1). For the IS1106 PCR, the thermocycler conditions were one cycle each of $37^{\circ} \mathrm{C}$ for $10 \mathrm{~min}$ and $95^{\circ} \mathrm{C}$ for $10 \mathrm{~min}$, followed by 32 cycles of $95^{\circ} \mathrm{C}$ for $25 \mathrm{~s}$, $61^{\circ} \mathrm{C}$ for $40 \mathrm{~s}$ and $72{ }^{\circ} \mathrm{C}$ for $1 \mathrm{~min}$. The $\operatorname{ctrA}$ PCR conditions were one cycle each of $50{ }^{\circ} \mathrm{C}$ for $5 \mathrm{~min}$ and $95^{\circ} \mathrm{C}$ for $10 \mathrm{~min}$ followed by 45 cycles of $95^{\circ} \mathrm{C}$ for $15 \mathrm{~s}$ and $60{ }^{\circ} \mathrm{C}$ for $1 \mathrm{~min}$. After the PCR, the IS 1106 PCRs were removed automatically from the thermocycler to a refrigerated block whilst the $c t r A$ PCRs were moved automatically to an integrated fluorescence reader. For the IS1106 PCR, analysis of DNA products was performed by gel electrophoresis on a $1.5 \%$ agarose gel containing ethidium bromide and visualized on a transilluminator. For the $\operatorname{ctr} A$ PCR, fluorescence emissions were analysed automatically as described previously (Diggle et al., 2001a).

PCR, nested PCR and DNA sequencing of porA from body fluids. DNA extracted from body fluids was subjected to separate standard PCRs and nested PCRs. The standard PCR was performed as for meningococcal cultures (for primers see Table 1). The nested PCR was performed initially with a first-round PCR using primers designed using

Table 1. Primers used for PCR amplification and sequencing of porA

\begin{tabular}{|c|c|c|c|}
\hline Primer & Gene target & Primer sequence $\left(5^{\prime} \rightarrow 3^{\prime}\right)$ & Reference \\
\hline \multicolumn{4}{|c|}{ Amplification primers } \\
\hline IS1106-1 & IS1106 & ATTATTCAGACCGCCGGCAG & Newcombe et al. (1996) \\
\hline IS1106-8 & IS1106 & TGCCGTCCTGCAACTGATGT & Newcombe et al. (1996) \\
\hline NMPD1F & porA & CGTAAGCAGATTGGCAGTCAGATTGC & This study \\
\hline NMPD1R & porA & GAAGACATATCGGGTGTTTGCCCGAT & This study \\
\hline PorA-F & porA & ATGCGAAAAAAACTTACCGCCCTC & Suker et al. (1994) \\
\hline PorA-R & porA & AATGAAGGCAAGCCGTCAAAAACA & Maiden et al. (1992) \\
\hline CtrAF & $\operatorname{ctr} A$ & TTGTGTGGAAGTTTAATTGTAGGATGC & Guiver et al. (2000) \\
\hline CtrAR & $\operatorname{ctr} A$ & TCAGATTGTTGCCCTAAAGAGACA & Guiver et al. (2000) \\
\hline \multicolumn{4}{|c|}{ Sequencing primers } \\
\hline porA-SF (103) & porA VR1 & AACGGATACGTCTTGCTC & Suker et al. (1994) \\
\hline porA-SR (8U) & porA VR2 and VR3 & TCCGTACGCTACGATTCTCC & Maiden et al. (1992) \\
\hline
\end{tabular}


the GeneFisher software (http://bibiserv.techfak.uni-bielefeld.de/ genefisher). The PCR was set up in a final volume of $50 \mu \mathrm{l}$ using $1 \cdot 1 \times$ Reddymix PCR master mix as before but using $1 \mu \mathrm{l}$ of each of primers NMPD1F and NMPD1R (Table 1). The PCR conditions were 25 cycles of $95^{\circ} \mathrm{C}$ for $1 \mathrm{~min}, 62^{\circ} \mathrm{C}$ for $1 \mathrm{~min}$ and $72{ }^{\circ} \mathrm{C}$ for $2 \mathrm{~min}$ followed by one cycle of $72{ }^{\circ} \mathrm{C}$ for $2 \mathrm{~min}$. After the PCR, the NCC plate was removed automatically from the thermocycler to a refrigerated block. The second-round PCR was then performed as for the genotypic characterization of N. meningitidis strains.

PCR product purification. A $40 \mu \mathrm{l}$ aliquot of each PCR product was subsequently transferred into a 384-well Millipore MultiScreen 384PCR filter plate. The plate was transferred automatically onto the integrated vacuum manifold and a vacuum of 450 mbar (approx. $30 \mathrm{~cm}$ $\mathrm{Hg}$ ) was applied for $20 \mathrm{~min}$. The PCR products were then resuspended in $30 \mu \mathrm{l} 18-\mathrm{M} \Omega$ distilled water by multi-pipetting a $15 \mu \mathrm{l}$ volume 20 times. This process removed unused primers and dNTPs.

PCR sequence-labelling. Aliquots of $11 \mu \mathrm{l}$ of each purified PCR product were transferred to two wells of a 96-well microtitre plate (one well for the forward direction and one well for the reverse direction). To these wells, $8 \mu$ l DYEnamic ET premix (Amersham Pharmacia Biotech) was added, followed by $1 \mu \mathrm{l}$ of the necessary primer at a concentration of 5 pmol to give a final volume of $20 \mu$ l. The sequencing cycle was 30 cycles of $92^{\circ} \mathrm{C}$ for $20 \mathrm{~s}, 50{ }^{\circ} \mathrm{C}$ for $15 \mathrm{~s}$ and $60{ }^{\circ} \mathrm{C}$ for $1 \mathrm{~min}$. Appropriate washing of the washable tip occurred with $18-\mathrm{M} \Omega$ distilled water throughout the procedure. The plate was placed automatically into the integrated thermocycler. Afterwards, the plate was removed automatically from the thermocycler and placed onto a refrigerated block.

Sequence product purification. All sequence products were adjusted to $20 \mu \mathrm{l}$ with $0.3 \mathrm{mM}$ EDTA and were transferred into a Millipore MultiScreen 384-SEQ plate and placed on the vacuum manifold. A pressure of $850 \mathrm{mbar}$ was applied for $20 \mathrm{~min}$ or until the plate was dry. The product was then washed in $25 \mu \mathrm{l} 0.3 \mathrm{mM}$ EDTA. Pressure was applied again at $850 \mathrm{mbar}$ for $5 \mathrm{~min}$ or until the plate was dry. Each sequence product was then resuspended in sterile distilled water with repeat pipetting. At this point, the samples were ready for injection on the MegaBACE DNA sequencer (Molecular Dynamics, Amersham Pharmacia Biotech) as outlined in the manufacturer's instructions.

Sequence interpretation of porA gene fragments. The sequence data were read automatically from the MegaBACE sequencer using the integrated image analysis and data collection software. Each gene sequence was downloaded onto a locally compiled database using DiscoverIR (Licor Biosciences UK). After sequence comparisons and appropriate editing, the nucleotide sequences from the porA VRs 1 and 2 were translated into amino acid sequences using the program TRANSLATE (http://ca.expasy.org/tools/dna.html) and submitted to the Neisseria meningitidis PorA Variable Region database (http://neisseria.org/ $\mathrm{nm} /$ typing/pora/) and were based on the scheme of Suker et al. (1994). New sequences located in VR1 or VR2 were assigned numbers through this database. Amino acid sequences for PorA VR3 were assigned names according to the same scheme as Suker et al. (1994), as performed in previous studies (Molling et al., 2000, 2001; Clarke et al., 2001b).

\section{RESULTS}

\section{Phenotypic characterization of $\mathbf{N}$. meningitidis strains}

Specimens were sent from a total of 555 patients with suspected meningococcal disease in Scotland between January and June 2001. Cultures isolated from blood or CSF were received from patients with meningococcal disease.
There were 35 isolates of $N$. meningitidis from 31 different patients received by the SMPRL for confirmation and typing (Table 2). Twenty-five were from blood and ten were from CSF. They were identified as serogroups B (18), C (11) and W135 (4), with two being non-groupable. Serotype information was not available for 15 isolates but serosubtype information was available for all isolates.

\section{Genotypic characterization of $\boldsymbol{N}$. meningitidis strains}

porA gene sequencing was performed on all $35 \mathrm{~N}$. meningitidis strains to gain nucleotide sequence information for VRs 1, 2 and 3 (Table 2). All strains were successfully sequenced and provided 21 different porA types, the most common being $18-1,3,38$ and $22,14,36$.

\section{Meningococcal PCR from body fluids}

There were 538 requests for meningococcal PCR between January and June 2001. These were serum (314), plasma (118), CSF (102), endotracheal (ET) aspirate (2) and adrenal tissue (2). Of these, 20 samples from 17 different patients were positive by the IS1106 PCR method; these were from CSF (12), plasma (5), serum (1), ET aspirate (1) and adrenal tissue (1) (Table 3). Using the ctrA PCR method, only 13 of these were positive.

\section{PCR, nested PCR and DNA sequencing of porA from body fluids}

All 20 IS1106 PCR-positive samples were subjected to both the standard porA and nested porA PCR methods. Using the standard porA PCR, only six were positive; however, when the nested porA PCR was used, 15 samples from 14 different patients were positive and the DNA was used as a template for nucleotide sequencing. Information relating to the nucleotide sequence of VRs 1, 2 and 3 was gained from all 15 nested porA-positive samples (Table 3 ). Of the seven standard porA PCR positives, three were negative by the nested porA PCR method and there was insufficient DNA for nucleotide sequencing. Nucleotide sequence data gained from the samples reflected those of the culture isolates. For example, por $A$ VR sequences such as 5-1, 10-8, 36b and 18-1, 3, 38 were found, which are respectively common in serogroup $\mathrm{C}$ and W135 strains.

\section{DISCUSSION}

Surveillance of bacterial infections is important and leads to a better understanding of the epidemiology of disease. Molecular methods have further improved our knowledge of the population biology of some bacteria, and this has been exemplified by the use of multilocus enzyme electrophoresis and multilocus sequence typing (Diggle et al., 2001b). The development of vaccines relies on the availability of such data so that the design represents strains circulating in the community. The use of sequence-based systems for bacterial typing has been highlighted previously (Clarke et al., 2001b, 
Table 2. Phenotypic characterization and porA gene sequencing results for $N$. meningitidis isolates

Abbreviations: NG, non-groupable; NT, non-typable with mAbs; NST, non-subtypable with mAbs.

\begin{tabular}{|c|c|c|c|c|c|c|c|}
\hline \multirow[t]{2}{*}{ Isolate } & \multirow[t]{2}{*}{ Isolate type } & \multicolumn{3}{|c|}{ Phenotypic characterization } & \multicolumn{3}{|c|}{ porA VR sequence types } \\
\hline & & Serogroup & Serotype & Serosubtype & VR1 & VR2 & VR3 \\
\hline $01-1773$ & Blood & W135 & NT & P1.15 & $19-1$ & 16 & 36 \\
\hline $01-2667$ & Blood & $\mathrm{C}$ & $2 \mathrm{a}$ & P1.5 & $5-1$ & $10-8$ & $36-1$ \\
\hline $01-1647$ & Blood & $\mathrm{B}$ & NT & $\mathrm{P} 1.12,13$ & 19 & 13 & $35 \mathrm{a}$ \\
\hline $01-1624$ & Blood & B & NT & P1.9 & 22 & 9 & $35 \mathrm{a}$ \\
\hline $01-1138$ & CSF & B & NT & P1.9 & 22 & 9 & $35 \mathrm{a}$ \\
\hline $01-1678$ & CSF & W135 & NT & $\mathrm{P} 1.3,6$ & $18-1$ & 3 & 38 \\
\hline $01-1597$ & Blood & W135 & NT & P1.3 & $18-1$ & 3 & 38 \\
\hline $01-2362$ & CSF & B & NT & P1.16 & 7 & 4 & 37 \\
\hline 01-1801 & CSF & B & 15 & $\mathrm{P} 1.7,16$ & 7 & 16 & 35 \\
\hline 01-1711 & Blood & W135 & NT & P1.3 & $18-1$ & 3 & 38 \\
\hline $01-2767$ & CSF & $\mathrm{C}$ & $2 \mathrm{a}$ & $\mathrm{P} 1.2,5$ & 5 & 2 & $36 \mathrm{~b}$ \\
\hline 01-1575 & Blood & $\mathrm{C}$ & $2 \mathrm{a}$ & NST & 5 & 2 & 36 \\
\hline $01-3328$ & Blood & B & NT & $\mathrm{P} 1.14$ & 22 & 14 & 36 \\
\hline 01-1784 & Blood & B & NT & P1.3, 6 & $18-1$ & 3 & 38 \\
\hline 01-1506 & Blood & B & 1 & $\mathrm{P} 1.13$ & 19 & 13 & 36 \\
\hline $01-2210$ & Blood & B & NT & P1.9 & 22 & 9 & $35 a$ \\
\hline $01-2398$ & Blood & B & NT & P1.16 & 19 & 16 & $38-1$ \\
\hline $01-2757$ & CSF & B & 1 & $\mathrm{P} 1.14$ & 22 & 14 & 36 \\
\hline $01-2729$ & Blood & B & NT & P1.9 & 20 & 9 & $35 a$ \\
\hline $01-1638$ & Blood & B & 4 & NST & $19-1$ & 15 & 36 \\
\hline $01-2782$ & Blood & $\mathrm{C}$ & $2 a$ & P1.5 & $5-1$ & $10-8$ & $36-1$ \\
\hline $01-1446$ & CSF & B & NT & P1.5 & $5-1$ & $10-4$ & 36 \\
\hline $01-1470$ & Blood & B & NT & P1.5 & $5-1$ & $10-4$ & 36 \\
\hline $01-1152$ & Blood & $\mathrm{C}$ & $2 \mathrm{a}$ & NST & 5 & 2 & 38 \\
\hline $01-2782$ & Blood & $\mathrm{C}$ & $2 \mathrm{a}$ & P1.5 & $5-1$ & $10-1$ & 36 \\
\hline $01-2948$ & Blood & B & 14 & $\mathrm{P} 1.14$ & 22 & 14 & 36 \\
\hline 01-1430 & Blood & B & 4 & P1.16 & 19 & 16 & $38-1$ \\
\hline 01-2979 & Blood & $\mathrm{C}$ & $2 \mathrm{a}$ & P1.5 & $5-1$ & $10-8$ & $36-1$ \\
\hline 01-2035 & Blood & $\mathrm{C}$ & $2 \mathrm{a}$ & $\mathrm{P} 1.2,5$ & 5 & 2 & $36-1$ \\
\hline $01-3166$ & CSF & NG & 1 & $\mathrm{P} 1.14$ & 22 & 14 & 36 \\
\hline $01-3167$ & Blood & NG & 1 & P1.14 & 22 & 14 & 36 \\
\hline $01-3326$ & Blood & $\mathrm{C}$ & $2 a$ & P1.5 & $5-1$ & $10-8$ & $36-1$ \\
\hline $01-2980$ & CSF & $\mathrm{C}$ & $2 \mathrm{a}$ & P1.15 & $5-1$ & $10-8$ & $36-1$ \\
\hline 01-1308 & CSF & B & 14 & P1.6, 3 & $18-1$ & 3 & 38 \\
\hline 01-3181 & Blood & $\mathrm{C}$ & $2 b$ & $\mathrm{P} 1.2,5$ & 5 & 2 & $36-1$ \\
\hline
\end{tabular}

c; Maiden et al., 1998) and the SMPRL currently provides a national genotyping service for the characterization of $N$. meningitidis cultures by multilocus sequence typing and por $A$ gene sequencing (Clarke et al., 2001c). Such systems can often provide rapid results when cultures are available and can be useful for public health management (Clarke et al., 2001b; Feavers et al., 1999). The provision of these data also provides long-term surveillance data that can be used for informing vaccine policy.

There is an urgent need for a vaccine against serogroup B meningococci, as this serogroup is now the most common cause of infection in many countries (Connolly \& Noah, 1999). Since the introduction of meningococcal serogroup $C$ conjugate vaccines in the $\mathrm{UK}$, there has been a decrease in the incidence of serogroup C disease, and serogroup B is therefore even more predominant. OMP vaccines may provide a short-term solution to this problem by providing protection in countries where a limited number of serosubtypes exist, although they are unlikely to eliminate endemic disease. However, information is required on the sequence variation of OMPs and studies of meningococcal cultures have been performed that indicate such variation (Molling et al., 2000; Clarke et al., 2001b). In the present study, we have shown that 
Table 3. Serogrouping and serosubtyping data from non-culture-confirmed cases of meningococcal disease

\begin{tabular}{|c|c|c|c|c|c|c|c|c|c|}
\hline \multirow[t]{2}{*}{ Sample } & \multirow[t]{2}{*}{ Sample type } & \multirow[t]{2}{*}{ Serogroup } & \multicolumn{4}{|c|}{ PCR } & \multicolumn{3}{|c|}{ porA VR sequence types } \\
\hline & & & IS1106 & ctrA & porA & $\begin{array}{c}\text { porA } \\
\text { nested }\end{array}$ & VR1 & VR2 & VR3 \\
\hline 01-1062 & ET aspirate & $\mathrm{C}$ & + & + & - & + & $5-1$ & $10-8$ & $36 b$ \\
\hline 01-1415 & CSF & NG & + & + & - & + & $7-2$ & 4 & 37 \\
\hline $01-1500$ & Plasma & NG & + & + & - & + & $5-1$ & $10-8$ & $36 b$ \\
\hline 01-1501 & Adrenal tissue & NG & + & + & - & + & $5-1$ & $10-8$ & $36 b$ \\
\hline 01-1505 & CSF & NG & + & + & - & + & $5-1$ & $10-4$ & $36 b$ \\
\hline 01-1755 & Plasma & NG & + & - & - & + & $18-1$ & 3 & 38 \\
\hline 01-1970 & Serum & NG & + & - & - & + & $7-2$ & 4 & 37 \\
\hline $01-2124$ & CSF & $\mathrm{C}$ & + & + & + & + & $5-1$ & $10-8$ & $36 \mathrm{~b}$ \\
\hline $01-2187$ & CSF & NG & + & + & - & + & $7-2$ & 4 & 37 \\
\hline $01-2711$ & Plasma & NG & + & + & - & + & $5-1$ & $10-8$ & $36 b$ \\
\hline $01-2877$ & CSF & B & + & + & + & + & 22 & 14 & 36 \\
\hline 01-2981 & CSF & $\mathrm{C}$ & + & + & + & + & $5-1$ & $10-8$ & $36 b$ \\
\hline 01-3183 & CSF & $\mathrm{C}$ & + & + & - & + & 5 & 2 & $36 \mathrm{~b}$ \\
\hline $01-3251$ & Plasma & NG & + & - & - & + & 5 & 2 & $36 b$ \\
\hline 01-3368 & CSF & NG & + & - & - & + & $5-2$ & $10-1$ & $36 b$ \\
\hline 01-1290 & Plasma & NG & + & + & - & - & NA & $\mathrm{NA}$ & NA \\
\hline 01-1852 & CSF & NG & + & + & - & - & NA & $\mathrm{NA}$ & NA \\
\hline 01-2124 & CSF & NG & + & - & + & - & $\mathrm{NA}$ & $\mathrm{NA}$ & NA \\
\hline 01-2877 & CSF & NG & + & - & + & - & NA & $\mathrm{NA}$ & NA \\
\hline 01-2981 & CSF & NG & + & - & + & - & $\mathrm{NA}$ & $\mathrm{NA}$ & NA \\
\hline
\end{tabular}

NA, Not applicable.

a nested PCR approach can be used to provide nucleotide sequence data and therefore serosubtype information relating to the infecting meningococcus. All IS1106 PCR-positive clinical samples were tested by $\operatorname{ctr} A$, porA and nested porA PCRs. Interestingly, seven samples were $c t r A$ PCR-negative. All ctrA PCR-negative samples were non-groupable, so this could be explained by meningococci not possessing the genes necessary for capsule expression, as reported by Claus et al. (2002). Of the seven $c t r A$ PCR-negative samples, three were porA PCR-positive and four were nested porA PCR-positive; although potential false-positives have been reported when using IS 1106 as a target (Borrow et al., 1998b), this was clearly not the case in this study. This would result in three positive results being missed in laboratories using the ctrA PCR method even though some laboratories use the fluorescencebased ctrA PCR assay (Guiver et al., 2000; Diggle et al., 2001a).

Fifteen samples were nested porA PCR-positive and were therefore suitable for nucleotide sequencing. Although three non-nested porA PCRs were positive, there was insufficient DNA present for nucleotide sequencing. Nucleotide sequence data from the three VRs analysed indicated variation amongst strains causing invasive disease. The nucleotide sequence data gained after nested porA PCR were comparable to those gained from nucleotide sequencing directly from isolates.
The results presented here indicate that a nested porA PCR method increased the overall serosubtype data gained from meningococci causing disease in a given population. Without such a method, the amount of information is severely reduced. In the present study, the amount of serosubtype information was increased by $45 \%$ when the nested por $A$ nucleotide sequencing results were included, even taking into account multiple specimens from the same patient. Therefore, this method increases the amount of information available for public health management of cases and their contacts. It also provides data for vaccine design, which may have an impact on the design and development of OMP vaccines against serogroup B meningococci.

\section{ACKNOWLEDGEMENTS}

Funding for the liquid-handling robots and automated DNA sequencers was generously provided by the Meningitis Association (Scotland) and National Services Division of the Scottish Executive. The authors also wish to thank microbiologists from Scotland for sending meningococcal isolates to the SMPRL.

\section{REFERENCES}

Al'Aldeen, A. A. \& Cartwright, K. A. (1996). Neisseria meningitidis: vaccines and vaccine candidates. J Infect 33, 153-157.

Borrow, R., Claus, H., Guiver, M., Smart, L., Jones, D. M., Kaczmarski, 
E. B., Frosch, M. \& Fox, A. J. (1997). Non-culture diagnosis and serogroup determination of meningococcal $\mathrm{B}$ and $\mathrm{C}$ infection by a sialyltransferase (siaD) PCR ELISA. Epidemiol Infect 118, 111-117.

Borrow, R., Claus, H., Chaudhry, U., Guiver, M., Kaczmarski, E. B., Frosch, M. \& Fox, A. J. (1998a). sia D PCR ELISA for confirmation and identification of serogroup Y and W135 meningococcal infections. FEMS Microbiol Lett 159, 209-214.

Borrow, R., Guiver, M., Sadler, F., Kaczmarski, E. B. \& Fox, A. J. (1998b). False positive diagnosis of meningococcal infection by the IS1106 PCR ELISA. FEMS Microbiol Lett 162, 215-218.

Clarke, S. C., Diggle, M. A. \& Edwards, G. F. (2001a). Automated nonculture-based sequence typing of meningococci from body fluids. $\mathrm{Br}$ Biomed Sci 58, 230-234.

Clarke, S. C., Diggle, M. A. \& Edwards, G. F. (2001b). Semiautomation of multilocus sequence typing for the characterization of clinical isolates of Neisseria meningitidis. J Clin Microbiol 39, 3066-3071.

Clarke, S. C., Diggle, M. A., Reid, J. A., Thom, L. \& Edwards, G. F. (2001c). Introduction of an automated service for the laboratory confirmation of meningococcal disease in Scotland. J Clin Pathol 54, $556-557$.

Clarke, S. C., Reid, J., Thom, L., Denham, B. C. \& Edwards, G. F. (2002). Laboratory confirmation of meningococcal disease in Scotland, 1993-9. J Clin Pathol 55, 32-36.

Claus, H., Maiden, M. C. J., Maag, R., Frosch, M. \& Vogel, U. (2002). Many carried meningococci lack the genes required for capsule synthesis and transport. Microbiology 148, 1813-1819.

Connolly, M. \& Noah, N. (1999). Is group C meningococcal disease increasing in Europe? A report of surveillance of meningococcal infection in Europe 1993-6. European Meningitis Surveillance Group. Epidemiol Infect 122, 41-49.

Corless, C. E., Guiver, M., Borrow, R., Edwards-Jones, V., Fox, A. J. \& Kaczmarski, E. B. (2001). Simultaneous detection of Neisseria meningitidis, Haemophilus influenzae, and Streptococcus pneumoniae in suspected cases of meningitis and septicemia using real-time PCR. J Clin Microbiol 39, 1553-1558.

Diggle, M. A., Edwards, G. F. S. \& Clarke, S. C. (2001a). Automation of fluorescence-based PCR for confirmation of meningococcal disease. J Clin Microbiol 39, 4518-4519.

Diggle, M. A., Edwards, G. F. S. \& Clarke, S. C. (2001b). Developments in the diagnosis of meningococcal disease and the characterization of Neisseria meningitidis. Rev Med Microbiol 12, 211-217.

Eldridge, J., Sutcliffe, E. M., Abbott, J. D. \& Jones, D. M. (1978). Serological grouping of meningococci and detection of antigen in cerebrospinal fluid by coagglutination. Med Lab Sci 35, 63-66.

Feavers, I. M., Fox, A. J., Gray, S., Jones, D. M. \& Maiden, M. C. (1996). Antigenic diversity of meningococcal outer membrane protein PorA has implications for epidemiological analysis and vaccine design. Clin Diagn Lab Immunol 3, 444-450.

Feavers, I. M., Gray, S. J., Urwin, R., Russell, J. E., Bygraves, J. A., Kaczmarski, E. B. \& Maiden, M. C. (1999). Multilocus sequence typing and antigen gene sequencing in the investigation of a meningococcal disease outbreak. J Clin Microbiol 37, 3883-3887.

Finne, J., Bitter-Suermann, D., Goridis, C. \& Finne, U. (1987). An IgG monoclonal antibody to group B meningococci cross-reacts with developmentally regulated polysialic acid units of glycoproteins in neural and extraneural tissues. J Immunol 138, 4402-4407.

Frasch, C. E., Zollinger, W. D. \& Poolman, J. T. (1985). Serotype antigens of Neisseria meningitidis and a proposed scheme for designation of serotypes. Rev Infect Dis 7, 504-510.

Guiver, M., Borrow, R., Marsh, J., Gray, S. J., Kaczmarski, E. B., Howells,
D., Boseley, P. \& Fox, A. J. (2000). Evaluation of the Applied Biosystems automated Taqman polymerase chain reaction system for the detection of meningococcal DNA. FEMS Immunol Med Microbiol 28, 173-179.

Hayrinen, J., Jennings, H., Raff, H. V., Rougon, G., Hanai, N., GerardySchahn, R. \& Finne, J. (1995). Antibodies to polysialic acid and its Npropyl derivative: binding properties and interaction with human embryonal brain glycopeptides. J Infect Dis 171, 1481-1490.

Jelfs, J., Munro, R., Wedege, E. \& Caugant, D. A. (2000). Sequence variation in the porA gene of a clone of Neisseria meningitidis during epidemic spread. Clin Diagn Lab Immunol 7, 390-395.

Maiden, M. C., Suker, J., McKenna, A. J., Bygraves, J. A. \& Feavers, I. M. (1991). Comparison of the class 1 outer membrane proteins of eight serological reference strains of Neisseria meningitidis. Mol Microbiol 5, 727-736.

Maiden, M. C., Bygraves, J. A., McCarvil, J. \& Feavers, I. M. (1992). Identification of meningococcal serosubtypes by polymerase chain reaction. J Clin Microbiol 30, 2835-2841.

Maiden, M. C., Bygraves, J. A., Feil, E. \& 10 other authors (1998). Multilocus sequence typing: a portable approach to the identification of clones within populations of pathogenic microorganisms. Proc Natl Acad Sci U S A 95, 3140-3145.

McGuinness, B. T., Lambden, P. R. \& Heckels, J. E. (1993). Class 1 outer membrane protein of Neisseria meningitidis: epitope analysis of the antigenic diversity between strains, implications for subtype definition and molecular epidemiology. Mol Microbiol 7, 505-514.

Molling, P., Unemo, M., Backman, A. \& Olcen, P. (2000). Genosubtyping by sequencing group $\mathrm{A}, \mathrm{B}$ and $\mathrm{C}$ meningococci; a tool for epidemiological studies of epidemics, clusters and sporadic cases. APMIS 108, 509-516.

Molling, P., Backman, A., Olcen, P. \& Fredlund, H. (2001). Comparison of serogroup W-135 meningococci isolated in Sweden during a 23-year period and those associated with a recent hajj pilgrimage. J Clin Microbiol 39, 2695-2699.

Newcombe, J., Cartwright, K., Palmer, W. H. \& McFadden, J. (1996). PCR of peripheral blood for diagnosis of meningococcal disease. J Clin Microbiol 34, 1637-1640.

Ni, H., Knight, A. I., Cartwright, K., Palmer, W. H. \& McFadden, J. (1992). Polymerase chain reaction for diagnosis of meningococcal meningitis. Lancet 340, 1432-1434.

Olcen, P., Danielsson, D. \& Kjellander, J. (1975). The use of protein Acontaining staphylococci sensitized with anti-meningococcal antibodies for grouping Neisseria meningitidis and demonstration of meningococcal antigen in cerebrospinal fluid. Acta Pathol Microbiol Scand B 83, 387-396.

Rappuoli, R. (2001). Conjugates and reverse vaccinology to eliminate bacterial meningitis. Vaccine 19, 2319-2322.

Rosenstein, N. E., Fischer, M. \& Tappero, J. W. (2001). Meningococcal vaccines. Infect Dis Clin North Am 15, 155-169.

Saunders, N. B., Zollinger, W. D. \& Rao, V. B. (1993). A rapid and sensitive PCR strategy employed for amplification and sequencing of porA from a single colony-forming unit of Neisseria meningitidis. Gene 137, 153-162.

Smith, N. H., Maynard Smith, J. \& Spratt, B. G. (1995). Sequence evolution of the porB gene of Neisseria gonorrhoeae and Neisseria meningitidis: evidence of positive Darwinian selection. Mol Biol Evol $12,363-370$.

Suker, J., Feavers, I. M., Achtman, M., Morelli, G., Wang, J. F. \& Maiden, M. C. (1994). The porA gene in serogroup A meningococci: evolutionary stability and mechanism of genetic variation. Mol Microbiol 12, $253-265$. 
Urwin, R., Kaczmarski, E. B., Guiver, M., Fox, A. J. \& Maiden, M. C. (1998a). Amplification of the meningococcal porB gene for non-culture serotype characterization. Epidemiol Infect 120, 257-262.

Urwin, R., Fox, A. J., Musilek, M., Kriz, P. \& Maiden, M. C. (1998b).

Heterogeneity of the PorB protein in serotype 22 Neisseria meningitidis. J Clin Microbiol 36, 3680-3682.
Urwin, R., Feavers, I. M., Jones, D. M., Maiden, M. C. \& Fox, A. J. (1998c). Molecular variation of meningococcal serotype 4 antigen genes. Epidemiol Infect 121, 95-101.

van der Ley, P., Heckels, J. E., Virji, M., Hoogerhout, P. \& Poolman, J. T. (1991). Topology of outer membrane porins in pathogenic Neisseria spp. Infect Immun 59, 2963-2971. 